\title{
Validity through Dialogue
}

\author{
ABSTRACT
}

Teaching \& Learning Inquiry takes responsibility for engaging in what Senge (2006) calls "reflective openness," encouraging a range of appropriate epistemologies to study teaching and learning. The journal, like its parent organization, embodies the role of "intermediary" through the practice of continual examination of ideas and the provisions of "stability, expert depth, and fieldwide reach" (Bacchetti \& Ehrlich, 2006) for the Scholarship of Teaching and Learning.

\section{KEYWORDS}

reflective openness, intermediary, stability, expert depth, fieldwide reach, hermeneutics, deliberative democracy, transformation

In the book The Fifth Discipline (2006), Senge advises that transformative change can occur when genuine openness is present. He calls for "reflective openness," which "looks inward and starts with the willingness to challenge our own thinking, to recognize that any certainty we have is, at best, a hypothesis about the world. It involves not just examining our own ideas, but mutually examining others' thinking" (p. 278).

As the International Society for the Scholarship of Teaching and Learning (ISSOTL) was formed, leaders adopted Senge's reflective openness as a basic tenet. Those who were convinced that the academy could be transformed positively by expanding its acceptance of scholarship about teaching and learning committed to examining and reexamining that conviction and to continuing to interact in scholarship and in practice with those still holding a narrower view of research. We believed that an organization like ISSOTL can, in fact, serve as an intermediary, a term used by Bacchetti and Ehrlich in their book Reconnecting Education and Foundations (2006). They contend that "a wide range of intellectual resources, experience, and perspectives" improve chances for making needed changes in education. They state that "intermediary organizations offer the stability, expert depth, and fieldwide reach to make assembling and circulating elements of educational capital a signal contribution to their constituents" (p. 43).

In an early newsletter piece when I served as the first elected president of the International Society for the Scholarship of Teaching and Learning, I wrote with hope that ISSOTL would be a potent intermediary, spanning countries and fields as it circulated ideas, practices, and scholarly findings (2007). And, in fact, ISSOTL has developed into just such an international community that links scholars from many disciplines and many traditions as they work to understand and influence teaching and learning. 
Now ISSOTL launches another means of supporting those diverse scholars. My hope and conviction is that this journal can embody and expand this practice of continual examination of ideas and "the stability, expert depth, and fieldwide reach" that characterize the organization.

Early on when the Carnegie Academy for the Scholarship of Teaching and Learning was launched, some of us sat around a table in Palo Alto, California, attempting to define what we meant by the Scholarship of Teaching and Learning. When I volunteered to draft a definition, I didn't realize what I was getting into. For example, one draft in a sequence of sacrificial drafts used the word epistemological to describe the basis for scholarly approaches. Colleagues quickly deleted that word as unnecessarily complicating the definition with academic jargon.

You'd think I would have learned, but I'm going to use the word epistemological again as I welcome this journal and point to its potential for a unique position among academic journals. I need the concept and the word to suggest a dialogic approach to both what appears in the journal and how it gets here.

In the field of assessment of learning, we seem to be all about standardization. Firmly grounded in the epistemology of educational measurement-one discipline among many in higher education - this standardized perspective contends that we must all decide that the same things are important and measure them in strictly uniform ways in order to create valid judgments. According to this perspective, variance is a problem or error to be erased or removed. If the types of evidence are varied or if the judgments of multiple interpreters of that evidence differ to any great extent, the assessment process lacks validity.

Rather than assuming that evidence must be uniform, however, we might start from two other questions: "How do we most fairly and productively have consequential discussions about diverse evidence?" and "What kinds of conversations and what kinds of evidence do we need to have for such a discussion?" In other words, "How can we best articulate, understand, and make decisions in the face of multiple perspectives on what to value?"

Two epistemological traditions from social science and the humanities offer counterpoints to traditional educational measurement. In hermeneutics and in deliberative democracy, a central premise is that the validity of a decision-making process rests in the degree to which it adheres to conversational norms. From this perspective, it is more important to focus on the standards we enact in how we talk to each other about evidence and criteria than to focus on standardizing evidence and criteria before the conversation begins. How we talk, who has a voice, and how we construct the relationship between discussion and action are all key concerns.

The tradition of hermeneutics points to an integrated approach that combines different sources of evidence into a body of evidence. This evidence, however, is approached iteratively, with the continued interaction of the evidence providing the most accurate source about the learning revealed through the evidence. During this iterative approach, readers recognize and engage their biases, illuminating and mediating them rather than trying to eliminate them. They look for their assumptions and try to understand what influences them as readers of the evidence. The aim is mutual comprehensibility in assessing what they read and see.

The tradition of deliberative democracy assumes reasonableness as a norm that values and respects disagreement based on identified, articulated reason. Although affirmations 
and decisions have to be made at particular times, such as in the context of a journal when submitting or reviewing an article, an openness to changing viewpoints and decisions over time is required.

Let's challenge ourselves in Teaching \& Learning Inquiry to create a site for dialogue, not as a respite from traditional standards of scholarly work but as an alternative and valid way of engaging in scholarship and in deciding what and how to share with one another. Enacting publication practices that welcome multiple voices, encourage diverse points of view expressed well and civilly, and link what we write and read to what we do will make our publication consonant with our organization. By engaging in reflective openness, serving as an intermediary among diverse ideas and people, and adopting appropriate epistemologies, Teaching \& Learning Inquiry can contribute to transformative change.

Barbara Cambridge directs the Washington office of the National Council of Teachers of English (NCTE) and co-directs the Inter/National Coalition for Electronic Portfolio Research.

\section{REFERENCES}

Bacchetti, R., \& Ehrlich, T. (2006). Reconnecting education and foundations: Turning good intentions into educational capital. San Francisco, CA: Jossey-Bass.

Cambridge, B. (2007). ISSOTL as intermediary: 'Stability, Depth, and Field-wide Reach. The International Commons. 2(2). p.1.

Senge, P. M. (2006). The Fifth discipline: The Art and practice of the learning organization. New York, NY: Currency/Doubleday. 